\title{
Postgraduate surgical education
}

\section{Educación quirúrgica en posgrado}

\author{
Jesús Tapia-Jurado ${ }^{*}$ and Yohevane García-Barrón ${ }^{2}$ \\ ${ }^{1}$ Chairman of the Medical Academy of Surgery, Coordinator of Postgraduate Advanced Surgical Courses; ${ }^{2}$ Coordinator of Postgraduate Advanced \\ Surgical Courses. Faculty of Medicine, UNAM, Mexico City, Mexico
}

Surgery is born with humankind itself, but it is not until the last 50 years that it has been able to offer patients less traumatic and safer surgical procedures. In the field of surgery professionals' education, it is fair to recognize the work carried out by the Division of Postgraduate Studies of the National Autonomous University of Mexico Faculty of Medicine through the Single Program for Medical Specializations (PUEM Programa Único de Especializaciones Médicas) ${ }^{1}$, always thinking on the benefit of residents and teachers, but especially of Mexican society. This is why we consider we should continue to collaborate with educational and health institutions, as well as with certification bodies, and together analyze our concerns, wishes and experiences, and thus reach a new moment for the curriculum and study programs of the various surgical specialties to be updated.

Advances in basic and clinical sciences have allowed the generation of new knowledge to support the surgical patient, including the management of the inflammatory and metabolic response of the critically ill surgical patient, more timely and accurate diagnoses thanks to imaging and endoscopy technologies, parenteral nutritional support, advances in anesthesia and ventilation, and pharmacological treatments (antibiotics, analgesics, antithrombotic agents); all this associated with less traumatic and safer surgical approaches, such as minimally invasive surgery and robotics. All this results in the appearance of a large body of knowledge and skills that must be taught in a limited time, which forces us to select what, how, how deeply and at what moment should knowledge and manual skills of the future surgeon be taught and learned. For this reason, teaching in medical residencies should focus on the needs of the students, the pathologies to be faced by each specialty and the characteristics of the hospital units where residents are going to work. In addition, we must take the neurobiological concepts ${ }^{2}$ of learning into account, i.e. repetition of knowledge through diverse strategies until it becomes reflective and critical, repetition of manual skills until dexterity is achieved, motivation, visualization of concepts, reward, moderate and controlled stress that does not lead to exhaustion and anxiety, broad personal commitment, multitasking without attention dispersion, understanding that each resident has a different learning style, reinforcing active participation of the teacher-student binomial, and systematically reviewing knowledge by means of scientific evidence. Therefore, we are obliged to offer updated, state-of-the-art curriculums and study programs that cover the essential professional competences for the health needs of the Mexican population (prevention, diagnosis, treatment and rehabilitation of the medical-surgical pathologies of each specialty, in addition to providing care with the best quality, safety and cost-benefit ratio). In addition, study plans should be consistent with the public assistance policies required by health institutions.

As regards teaching strategies, they should be interactive and include problem-based learning, evidence and result-based medicine, basic-clinical integration, simulation-acquired surgical skills and dexterities, and distance education. For theory, sessions exclusively

\footnotetext{
Correspondence:

*Academia Mexicana de Cirugía

Av. Cuauhtémoc $330,3^{\circ}$ Bloque B

Unidad de Congresos

Centro Médico Nacional Siglo XXI

Col. Doctores

C.P. 06720, Ciudad de México, México

E-mail: tapiajj@amcg.org.mx
}

Date of reception: $16-10-2017$

Date of acceptance: 20-12-2017

DOI: 10.24875/CIRUE.M18000017
Cir Cir. 2018;86:107-109

Contents available at PubMed www.cirugiaycirujanos.com 
directed to resident physicians of different academic years are advised; we are not referring to hospital compulsory sessions (clinical-surgical, anatomical-pathological, imaging, tissue management, ethics, etc. sessions, which are to be attended as well), but these sessions are beyond the clinical-hospital scope, in small groups, where the resident's opportunity to participate is broad and unlimited, coordinated by his/her tutor or by the resident with the highest rank, and having clinical discussions, with emphasis on the reasoning and reflection about diagnosis, medical-surgical treatment, prognosis, rehabilitation, management of postoperative complications and ethical issues, without forgetting that clinical approach must continue at the patient bedside, who is the essence of educational work. With regard to medical-surgical skills, it is necessary to identify the essential ones the resident must acquire, to what degree of mastery (novice, competent, expert) and whether he/she should carry out each procedure a particular number of times to acquire expertise. In addition, surgical practice should be broadened in an environment that reproduces reality in a controlled manner, with the purpose to acquire or improve psychomotor, communication, coordination and leadership professional competences. We are talking about the educational strategy of simulation ${ }^{3}$, which requires four stages: cognitive, integrative, autonomous and evaluation. Simulation can be carried out in non-biological and biological models, and can be simple or complex, inexpensive or expensive. All its modalities work as long as the learning objectives to be achieved are clear. Currently, simulation is regarded as an ethical necessity, since patients are protected by not becoming the learning object. The resident should also be trained with strong attachment to the scientific method, always wondering about the causes of the phenomena that alter health, the working hypotheses and the outcomes, which will lead to better decision making. Research works should be carried out, which can range from simple to complex issues, from a review of a clinical case to epidemiological surveys, comparative works and even studies with a large number of cases, with a control group and random assignment. We must always influence on the resident in order for him/her to carry out original works and avoid plagiarism or information repetition. Current surgeons should also aspire to have in their curricular development some type of master's degree or doctorate, which allows them to develop clinical or experimental medical research; therefore, we must insist on the pursue of a master's degree in surgical sciences.
To achieve a graduate profile of quality, it is necessary to include evaluation systems ${ }^{4}$ that demonstrate that residents acquired sufficient knowledge and skills to be competent in their profession, and that they will maintain a knowledge-seeking (learning to learn) and professional development attitude throughout their lives; examples of this are El Libro informático del residente in Spain, the eLogbook of the Royal College of Surgeons of Edinburgh in the United Kingdom, and national registries such as the Practice-Based Learning System and the National Surgical Quality Improvement Program (NSQIP), which are used in the USA.

Let us not forget that for every surgeon it is essential to maintain his/her ethical and bioethical principles for life, which should be reinforced or taught since the beginning of medical education. Therefore, it continues to be valuable fostering students' attitudes towards responsibility, honesty, humbleness, respect, professionalism, self-criticism, humanism, altruism, discretion, tolerance, leadership, social solidarity and protection of their surroundings and environment. In addition, other factors should be recognized and prevented, such as unnecessary surgery, surgical care in the final moments of life and implementation, development and adoption of new technologies. As for today's doctor teaching-learning process, it should be scientific, updated, humanistic and social, but most of all ethical ${ }^{5}$. According to some authors ${ }^{6}$, the principles to be applied are:

- Learning should be focused on the needs and characteristics of the student.

- The student must have enough time to learn and to practice the subjects he/she has been taught.

- The student should use appropriate learning strategies to retain the subjects he/she has learned.

- The student should be given the opportunity to explore the consequences of his/her learning.

- The student should be given the opportunity to practice the subjects he/she has learned.

To achieve these great objectives, the role of the teacher remains irreplaceable and he/she should continue to be the guide and tutor, the role model to be followed to follow and, why not, to be surpassed. Specialists such as Perry and Edwards ${ }^{7}$ point out that effective or exemplary teachers or tutors possess the following three fundamental competences:

- Educators as challengers, always seeking the highest expectations: you always can and you can even more! 
- Educators as positive motivators (affirmers), encouraging each students' activity and motivating them to show their progress and to recognize their own potential.

- Educators as influencers, which expresses a strong presence and large experience in the subjects that are taught.

On the other hand, it is important to note that some residents complain of overwork, exhaustion and lack of sleep, which leads, according to various reports ${ }^{8}$, to defective cognitive and manual skills learning, psychological alterations, marital problems, double motor vehicle accidents in relation to normal population, in addition to generating serious medical errors. For this reason, some international educational organizations have changed residents' working hours; the Accreditation Council for Graduate Medical Education established, since July 2003, a medical-surgical care work schedule of no more than 80 hours a week and on-call duties of no more than 30 continuous hours, with a subsequent break of at least 10 hours. Undoubtedly, it is difficult to reach an agreement on this point, since although it is true that by reducing medical-surgical care hours, residents' rest time is benefited and better quality and safety in patient medical care is favored, on the other hand, residents have their clinical-surgical experiences with hospitalized patients reduced.

Another subject that cannot be overlooked is residents' mistreatment, which some surgeons refer to as a usual, traditional and acceptable behavior. Quine ${ }^{9}$, in the United Kingdom, refers that $84 \%$ of young doctors have experienced at least one intimidating behavior and, in Latin America, situations of harassment or mistreatment of resident doctors range from 71 to $89 \%$. In Mexico ${ }^{10}$, the average number of residents who referred having been at least once victims of abuse, even if it was minimal, was $52.87 \%$, with surgical specialties registering the highest frequency of workplace violence, predominantly in general surgery, pediatric surgery and otorhinolaryngology. Therefore, it is time for teachers and residents to accept their responsibility and transform mistreatment into support, trust and solidarity. However, we must achieve a balance, since although it is true that the resident is overloaded with work, exhausted, sleepy and stressed, it is also true that the resident's tasks require order, discipline, great commitment and passion.

We should remember that, sometimes, in spite following all the relevant guidelines and standards, we find that, in surgical practice, unpredictable, non-preventable or unavoidable adverse events can occur. For this reason, adverse events occurring in medicine, and particularly in surgery, are a cause of great concern, which stands out since the publication of the book To err is human ${ }^{11}$ in 2001 . Therefore, generating quality and safety behaviors is indispensable in the training of health professionals.

For all the above, we believe that we must work together, universities and health institutions, in order to confront the challenges we must overcome in surgical education, which we summarize in the following points:

- Reviewing, developing and evaluating curriculums and study programs that cover the needs in terms of the clinical knowledge and surgical skills and abilities required by Mexican society, and that at the same time are linked to health institutions' interests.

- Educating on ethical, bioethical, professionalism and leadership principles.

- Encouraging cutting-edge and translational surgical research.

- Favoring surgical practice based on safe surgery.

- Maintaining continuous professional development.

\section{References}

1. Universidad Nacional Autónoma de México, México. Plan Único de Especializaciones Médicas (PUEM) en Cirugía General; c2009. (Consultado el 21 de septiembre de 2017.) Disponible en: http://www.sidep.fmposgrado.unam.mx:8080/fmposgrado/programas/cirgeneral.pdf

2. Friedlander MJ, Andrews L, Armstrong EG, Aschenbrenner C, Kass JS, Ogden $\mathrm{P}$, et al. What can medical education learn from the neurobiology of learning? Acad Med. 2011;86:415-20.

3. Tapia JJ, Vázquez A. Simulación como estrategia educativa en la adquisición de habilidades de destrezas quirúrgicas. En: Fenig RJ, editor. El entorno del cirujano general de principio a fin. Asociación Mexicana de Cirugía General, A.C. México; 2016. p. 131-6.

4. Escamirosa FP, Flores RMO, García IO, Vidal CRZ, Martínez AM. Face, content, and construct validity of the Endovis training system for objective assessment of psychomotor skills of laparoscopic surgeons. Surg Endosc. 2015;29:3392-403.

5. Fernández JM. Código de ética médica. Sociedad Mexicana de Ortopedia, A.C. México, D.F.; 2007. p. 109-11.

6. Guinchard SE. La ética en la formación del médico. Acta Ortopédica Mexicana. 2011;25:343-45.

7. Perry B, Edwards M. Exemplary online educators: creating a community of inquiry. Turkish Online Journal of Distance Education-TOJDE. 2005;6:46-54.

8. Mejía R, Diego A, Alemán M, Maliandi M, Lasala F. Percepción de maltrato durante la capacitación de médicos residentes. Medicina. 2005:65:366-8.

9. Quine $L$. Workplace bullying in junior doctors: questionnaire survey. BMJ. 2002;324:878-9.

10. Alcazar AL. Mobbing... Una manifestación de violencia en médicos residentes. Sesión conjunta con el Instituto de Seguridad y Servicios Sociales de los Trabajadores del Estado. México, D.F.: Academia Mexicana de Cirugía; 2017

11. Makary M, Daniel M. Medical error - the third leading cause of death in the US. BMJ. 2016;353:i2139. 